\title{
Diablotexto
}

\section{De Joseph Rojo a Pedro Royo: una aproximación biográfica a la figura de José Rojo, actor y dramaturgo áureo}

From Joseph Rojo to Pedro Royo: a biographical approach to the figure of José Rojo, actor and playwright of the Golden Age

SERGio Montalvo Mareca

UnIVERSIDAd Complutense de MADRID-INSTITUTO UnIVERSITARIO MenÉnDEZ PIDAL

Resumen: La figura de José Rojo plantea diferentes problemas relacionados con el reconocimiento de identidades. Rojo fue un dramaturgo áureo que se mantuvo fuera del canon literario debido al corto número de obras conocidas. Su identidad quedó fraccionada en otras más pequeñas, bien por las variantes del nombre, bien porque la crítica literaria no logró aunarlas en una sola. Son habituales las referencias a Josefe Rojo, Jusepe Roxo, Joseph Rojo o Pedro Royo, todas analizadas como sujetos diferentes y sin conexión. De esta necesidad se extrae el objetivo principal que lleva a cabo este artículo: enlazar las diferentes identidades de José Rojo en una sola para, así, presentar una visión única y certera de este autor que escribió durante la segunda mitad del siglo XVII.

Palabras clave: José Rojo, teatro, Siglo de Oro, biografía, identidad

Abstract: José Rojo, as a writer, poses different problems related to the certainty of his identity. Rojo was a playwright during the Spanish Golden Age. He remained outside the literary canon due to his scarce literary production and the low popularity of his work. His identity was divided into smaller identities because of the phonic and graphic variants of his name, and also because literary critics failed to interpret them as a single referent. José Rojo was also often known as Josefe Rojo, Jusepe Roxo, Joseph Rojo or Pedro Royo. All these variants were understood as different writers without any kind of connection. Therefore, this article exposes the different identities of José Rojo and combines them into a single person. As a result of this work, it is possible to present an unique and accurate view of this writer of the second half of the 17th century.

Key words: José Rojo, theatre, Golden Age, biography, identity 
Las palabras son para la luz, de noche se fugan, aunque el ardor de la persecución sea más febril y compulsivo a oscuras, pero también, por eso, más baldío. Pretender al mismo tiempo entender y soñar: ahí está la condena de mis noches.

Carmen Martín Gaite, El cuarto de atrás (1978).

\section{Introducción}

El periodo áureo es uno de los más interesantes y fructíferos de la literatura española. La otra cara de esta moneda es el elevado número de problemas que se advierten en los diferentes estudios que abordan esta franja. Una de las problemáticas más recurrentes en la literatura del Siglo de Oro, especialmente en aquellas figuras y obras que más se alejan del canon, es la relativa a la identidad. La anonimia, el uso de pseudónimos o la pérdida de las referencias de autoría son solo algunos ejemplos de las diferentes complicaciones que pueden encontrarse en esta clase de estudios filológicos.

Así sucede, entre muchos otros casos, con la figura de José Rojo, actor, poeta dramático, escribano y dialoguista, que vivió durante el siglo XVII en España. Para llevar a cabo esta tarea de visibilización tanto de la vida como de la obra del escritor, este artículo ha seguido una metodología basada en la revisión concienzuda y pormenorizada de todas aquellas fuentes e informaciones halladas hasta la fecha en las que figuran datos que posibiliten la reconstrucción de los distintos episodios de la vida del escritor áureo. El interés de este repaso bibliográfico se justifica a través del estado de la cuestión sobre la mencionada escasez de certezas en torno a la de José Rojo. En él, y a pesar de su brevedad — provocada por la falta de más datos-, se da cuenta de todas las informaciones recopiladas sobre el escritor hasta la fecha. El punto de mayor interés de este bloque radica en la aportación de un listado unificado en una sola figura de la producción literaria completa de José Rojo. Se suma, además, el diálogo vivista sobre la enseñanza de las mujeres titulado Espejo de ilustres y perfectas señoras, que hasta ahora no había sido considerado por parte de la crítica.

Hasta el momento no se tiene certeza de las fechas de su nacimiento ni tampoco de su muerte, por lo que no es posible proponer una horquilla temporal más precisa, aunque vivió durante el siglo XVII a la luz de los datos presentes 
en torno a sus obras ${ }^{1}$. En cambio, sí ha podido confirmarse que nació en Cuenca. De hecho, es él mismo quien lo afirma en el Espejo de ilustres y perfectas señoras, fechado cautelarmente circa 1670 (Montalvo Mareca, 2019a: 219-221). Allí se menciona también su lugar de residencia: "Compuesto por Josefe Rojo, veçino de la villa de Madrid y natural de la ziudad de Cuenca" (fol. 1v.).

Que José Rojo vivió y trabajó en Madrid es un hecho probado; de él dan debida cuenta los diferentes documentos que se han manejado para la redacción de este artículo y que se presentarán de manera sintética a lo largo de las páginas que siguen.

El mencionado Espejo de ilustres y perfectas señoras es la única obra de este escritor que no pertenece al género dramático. Se trata de una colección de ocho diálogos relativamente breves en los que siempre intervienen los dos mismos interlocutores, don Enrique (padre) y doña Blanca (hija), ambos pertenecientes al estado nobiliario. Los ocho textos se organizan en tres bloques, coincidiendo estos con los tres estados de la vida de la mujer, entiéndase juventud, madurez y vejez. Esta disposición le permite a Rojo caracterizar al personaje de don Enrique como el "maestro" y a doña Blanca como "discípula" según la disposición tradicional del diálogo hispánico (Gómez, 1988: 53-54). Así, el padre aconseja y guía a su descendiente a lo largo de los diferentes momentos de su vida para que siempre obre virtuosamente y no desacredite la fama de su familia.

Además de la estructura de personajes y las pocas cuestiones formales confirmadas (autoría, título y datación aproximada), debe mencionarse en relación a este diálogo su amplio abanico temático. La obra se yergue sobre tres grandes materias: la educación, la mujer y los estados de la vida. Asimismo, aunque de manera secundaria, se tratan otros temas, como el amor, la religión católica, la filosofía moral heredada de la Grecia clásica y de los Padres de la Iglesia y, en definitiva, todo aquello que puede englobarse dentro del marbete tradicional de "varia lección".

No existen otros datos sobre la faceta de Rojo como dialoguista más allá

\footnotetext{
1 Sobre la aproximación a las fechas de nacimiento y muerte de José Rojo, véase el razonamiento e hipótesis de Montalvo Mareca, 2019b, notas 4, 6 y 11.
} 
de los que han quedado aquí expuestos, que son el resultado de la sintetización de los que presenta Montalvo Mareca (2019b) en el registro no 328 de la base de datos de Dialogyca BDDH (Biblioteca Digital de Diálogo Hispánico). En síntesis, José Rojo no fue un autor de diálogo reputado, pues no existe constancia de que el Espejo de ilustres y perfectas señoras fuese conocido entre sus coetáneos; tampoco se registran noticias que den cuenta de que escribió otras obras de este mismo género.

No sucede lo mismo con su perfil como dramaturgo. Hasta el momento, se tiene constancia de que el conquense escribió, al menos, cuatro obras más: tres comedias y una loa. Estas son las que siguen: Las niñeces de Roldán, La esclavitud más dichosa o Virgen de los Remedios, Antíoco y Seleuco (comedia burlesca) y la Loa para la compañía de Vallejo de $1665^{2}$. La pieza breve es la única que está fechada. Aunque debió de representarse en 1665, no se publicó hasta 1676, donde formó parte de un volumen colectivo titulado Flor de entremeses, bayles y loas. En cambio, del resto de textos se desconoce la fecha de composición, publicación o estreno; aspecto que también comparte el Espejo de ilustres y perfectas señoras (Montalvo Mareca, 2019a).

Las dos primeras comedias están escritas en colaboración con Francisco de Villegas. Aunque el protagonista de este trabajo es Rojo, resulta ineludible aportar una breve nota sobre este Villegas, máxime cuando el tema de este monográfico son los problemas de identidad. McGaha identifica a Francisco de Villegas con el criptojudío Antonio Enríquez Gómez, autor, por ejemplo, de la Política angélica (1647); también conocido por el pseudónimo de Fernando de Zárate (McGaga, 1994: 298-303). Asimismo, McGaha defiende que Enríquez Gómez pudo elegir el sobrenombre de Francisco de Villegas para publicar aquellas comedias que podían poseer un trasfondo más incendiario.

Para el investigador, el pseudónimo escogido no tiene nada de azaroso,

\footnotetext{
2 La loa era una pieza breve de carácter dramático con la que se iniciaba la fiesta teatral. Solía ser el elemento más aséptico de todos cuantos conformaban la estructura teatral. En la mayor parte de las ocasiones, la loa funcionaba como una suerte de captatio benevolentiae hacia el público, mientras que en las representaciones palatinas servía para engrandecer a la figuraba que había financiado el espectáculo. Además, las loas podían tener una voluntad presentantiva, como sucede con Loa a la compañía de Vallejo de 1665, cuyo fin es dar cuenta de la composición de la compañía teatral de dicho autor de comedias para ese año en cuestión.
} 
pues buscaría establecer un juego gracias al parecido que tiene con Francisco de Quevedo y Villegas, que fue una de las personalidades que más duramente atacó a la comunidad judía. Sobre tal identificación entre Villegas y Enríquez Gómez volverá veinte años después la investigadora Elisa Domínguez de Paz (2014), a cuyas conclusiones, afines a las de su compañero, remito para no dilatar más este paréntesis.

En cuanto a la tercera comedia, y contrariamente a las conclusiones de algunos críticos — cuya nómina recoge Sánchez Mariana (1984: 121-130)—que sostenían que la comedia de Antíoco y Seleuco era anónima, parece que el texto fue el resultado de una triple colaboración atribuida a Rojo, Alonso de Olmedo y, aunque con menos certezas, a Juan de Matos Fragoso, como ya propuso Paz y Melia (1934: 29). Esta propuesta de atribución la recuperó, años más tarde, el equipo investigador del proyecto Manos.net en el registro de esta comedia (código 16-908), donde se ocuparon de probar la propuesta de autoría a través de diferentes análisis grafológicos que allí se detallan.

\section{Otras identidades para José Rojo: Joseph, Josefe, Jusepe y ¿Pedro Royo?}

Una de las primeras dificultades que debe considerar quien se aventure a estudiar una figura perteneciente a un periodo histórico anterior — sirve también para los lugares o, incluso, para cualquier tipo de palabra- es la consideración de todas las posibles variantes fónicas y gráficas del término que quiere localizarse. En el caso concreto de este trabajo, la forma “José Rojo" resulta de la modernización de lo que el propio autor escribe en el manuscrito autógrafo del Espejo de ilustres y perfectas señoras: "Josefe Rojo" (fol. 1 v) y "Joseph Rojo" (fol. 138). Forma modernizada de la que se valen también otros autores, como, por ejemplo, Varey y Davis (1992: 432) o Urzáiz Tortajada (2006: 241, 2002: 574), quien, en el trabajo más temprano, alterna con la variante "Jusepe". Asimismo, "José Rojo" es la voz que registra el DICAT en la entrada que dedica a Rojo (s.v. José Rojo).

Con todo, ninguna de estas tres es la que aparece con mayor frecuencia en los documentos de la época, ni tampoco en los trabajos posteriores que mencionan al autor. En ellos impera la forma "Jusepe Rojo". Es el caso de 
Domínguez Matito (2014: 135), García González (2012: 65), Sánchez Mariana (2009: 128-129), Cañas Murillo (2002-2003: 582) o Mackenzie, que también aporta la forma modernizada entre paréntesis como opción secundaria (1994: 182). Similar es también el caso de Shergold y Varey, quienes alternan las formas "José" y “Jusepe" (1985: 623).

Algo más compleja resulta la situación en la que se encuentra La Barrera (1860: 547 y 717) cuando considera que las formas "José Rojo" y “Jusepe Rojo" designan dos sujetos diferentes. Así, por ejemplo, afirma que la autoría de La esclavitud más dichosa y Virgen de los Remedios pertenece a Francisco de Villegas y a Jusepe Rojo (1860: 696); aunque en otros casos lo escribe así: "José (Jusepe) Rojo" (1860: 344 y 547). Pero registra una nueva entrada de autor para referirse a la autoría de la Loa para la compañía de Vallejo de 1665, que atribuye a un supuesto José Rojo que no es el anterior (1860: 717).

Tampoco el apellido "Rojo" quedó exento de estas variaciones. En determinadas fuentes aparece transcrito como "Royo", algo que dificulta más su identificación, pues las variantes del nombre podrían resultar más intuitivas. Es el caso de Paz y Melia (1934: № 226), que recoge “José Royo", lo que contrasta con los otros registros citados arriba en los que figura como José Rojo (no 1290 y no 2529).

En la breve mención que hace Crespo Matellán de la versión burlesca compuesta por Rojo, Matos y Olmedo de la comedia de Antíoco y Seleuco, el investigador atribuye la tercera jornada a «Jusepe Royo» (1979: 32). Existe una variante aún más endiablada que sí imposibilita, si no en su totalidad, al menos en un alto porcentaje, la identificación. Se trata de "Pedro Royo", recogida por Urzáiz Tortajada como autor de la comedia burlesca de Antíoco y Seleuco, sin una hipótesis concluyente sobre su génesis (2002: 580)

La existencia de todas estas maneras diferentes de transcribir el nombre de José Rojo complica los intentos de identificación por parte de la crítica, que no encuentra constancias suficientes para advertir que todas estas obras las escribió el mismo hombre. Lo mismo se observa en el OPAC de la Biblioteca Nacional de España, donde en el registro de autor aparece a nombre de "Joseph Rojo". A él se le atribuye la redacción del Espejo de ilustres y perfectas señoras, 
de Las niñeces de Roldán, de La esclavitud más dichosa o Virgen de los Remedios y de la Loa para la compañía de Vallejo de 1665. No obstante, de la Loa para la compañía de Vallejo de 1665 solo se menciona a "Joseph Rojo" en uno de los testimonios, el manuscrito 14834. Otros, en cambio, se vinculan al mismo autor que, según dicho OPAC, escribió Antíoco y Seleuco, es decir, a “Jusepe Rojo". Este es el caso de los testimonios R-1464, R-7896 y T-9087.

\section{Certezas biográficas localizadas}

La mayor parte de la información recuperada sobre la vida de José Rojo procede de documentación administrativa, habitualmente vinculada al ejercicio dramático: nóminas de miembros de una determinada compañía de actores, contratos para el alquiler de espacios o registros de asistencia, entre otros.

Como ya se mencionó antes, el primer dato biográfico de José Rojo sobre el que se tiene plena constancia es su lugar de nacimiento, Cuenca. A este hay que añadir que era "vecino de la villa de Madrid", como se señala en el diálogo mencionado (fol. 1v). Esta información se toma como auténtica puesto que procede de un manuscrito validado por el autor. Además, dado que Rojo no fue una figura principal de las letras del Seiscientos español, se ha desestimado cualquier hipótesis que atienda a una posible falsificación de los datos. A pesar de que no existen motivos reales para desconfiar de estas dos informaciones, se ha comprobado la veracidad de la firma que el dramaturgo estampó al concluir su diálogo. Para esto ha sido indispensable la localización de otra firma del dramaturgo, que ha permitido el cotejo de ambas y la comprobación de su veracidad.

Este documento no solo permite comprobar la autoría del manuscrito del Espejo de ilustres y perfectas señoras, sino que supone la primera prueba de su labor como actor. Se trata de un libro de cuentas procedente del Hospital General de Valencia donde se anuncia que el 30 de mayo de 1651 se depositó un dinero para pagar a los actores Miguel Bermúdez, Juan Coronel y José Rojo por veinte representaciones hechas en la casa de comedias, de modo que cobrasen siete libras por cada una de ellas (DICAT. s.v. Rojo, José, § 1651). El documento dice así: 
Nosotros Miguel bermudes, joan coronel y josepe Rojo comediantes hemos recibido del Sr. vitorino bonilla mayordomo del Hospital ciento y quarenta libras por el premio de veynte Representaciones que hemos de hazer y azemos en la Casa de las Comedias a razón de siete libras por representación, echo de mano agena y firmado de la nuestra oy a 30 de mayo de 1651. Juan Coronel, Joseph Rojo, Miguel Vermudes (Juliá Martínez, 1917: 73).

Al final del texto (fol. 42 r), los tres representantes firman a modo de conformidad. La firma de Rojo, que es la primera de las tres, coincide inequívocamente con la del manuscrito del Espejo de ilustres y perfectas señoras (fol. 138 r).

Por lo tanto, otra de las certezas sobre la vida de este autor es su trabajo como actor, y, como apuntan las fuentes, especializado en papeles de barba ${ }^{3}$ (Rennert, 1909: 580; Huerta Calvo, Peral Vega y Urzáiz Tortajada, 2005: 618; Shergold y Varey, 1985: 91). A partir del estudio de Shergold y Varey (1985) pueden extraerse otros datos adicionales que permiten perfilar esta faceta de José Rojo. El primero de ellos prueba que Rojo, en 1655, formaba parte de la compañía de Juan Pérez de Tapia, información que se completará más adelante a propósito de su membresía en la Cofradía de Nuestra Señora de la Novena y, posteriormente, de su cargo como tesorero en la misma.

El segundo deriva de Huerta Calvo, Peral Vega y Urzáiz Tortajada (2005: 618) y guarda relación con otras labores que desempeñó Rojo dentro de las compañías teatrales. Los investigadores atestiguan que fue copista para la compañía de Simón Aguado en 1662. Este dato parece derivar de otro de los testimonios analizados por Varey y Davis en su trabajo de 1973. Allí se menciona el papel que desempeñaba Rojo en la mencionada compañía: "28 de junio de 1662. Compañía de Simón Aguado, o por lo menos sus músicos. Retiro. El 27 de junio dijeron al escribano Jusepe Rojo y otros representantes que estaban ensayando..." (1973: 240).

Los autores continúan su aproximación a la figura de Rojo a través de la lista de obras escritas por él de las que se tiene noticia. Mencionan tanto la Loa para la compañía de Vallejo (1665) como la comedia intitulada La esclavitud más

\footnotetext{
3 Desde la época áurea, el término "barba" servía para denominar al actor maduro, aquel que se encontraba entre el galán (actor joven) y el viejo o vejete (de avanzada edad). Los barbas solían representar los papeles de padre, hermano, poderoso o noble, entre otros.
} 
dichosa y Virgen de los Remedios (que fechan en 1666). De igual forma, dan noticia de otra comedia, esta presuntamente perdida, cuyo título era El esclavo de María. Sin embargo, en la definición aportada no constan otros textos dramáticos del autor de las que sí se han conservado testimonios, como Antíoco y Seleuco, comedia burlesca o Las niñeces de Roldán, también en colaboración con Villegas - cuya posible vinculación con Enríquez Gómez sí señalan(Huerta Calvo, Peral Vega y Urzáiz Tortajada, 2005: 618).

Urzáiz Tortajada recupera la noticia de Antíoco y Seleuco en un trabajo posterior donde afirma que "existe una parodia de Antíoco y Seleuco con el mismo título, escrita por los actores José Rojo y Alonso de Olmedo" (2006: 241). El autor conoce la comedia a partir de la tesis doctoral de María José Casado Santos $(2005)^{4}$, donde lleva a cabo un fino análisis de textos teatrales burlescos, entre los que se encuentra dicha comedia de Rojo.

A la labor de copista de Rojo debe añadirse la de tesorero para la Cofradía de la Novena, según recogen Varey y Shergold: "en el de 28 dicho 1664, en que se le bolvió a elegir por Thesorero" (1973: 240). De la cita previa se infiere que el conquense ya había sido tesorero antes de 1664, año en el que renovó su cargo. El cargo de tesorero en la Cofradía de Nuestra Señora de la Novena, según demuestran los cálculos propuestos por los investigadores, era de carácter bianual, aunque con posibilidad de renovación (Varey Shergold, 1973: 240). En la misma fuente se menciona la entrada de Rojo a la Cofradía, que tuvo lugar en 1655, cuando este formaba parte de la compañía de Juan Pérez de Tapia.

Asimismo, el tesorero que precedió a Rojo fue su consuegro, Antonio de Rueda, autor de comedias y actor especializado en papeles de galán. Este ostentó el cargo de tesorero desde 1654 hasta su muerte en diciembre de 1662 (Pérez Pastor, 1901: 332). Rojo se hizo cargo entonces del puesto. La labor como tesorero del dramaturgo y dialoguista supone un dato inédito más sobre su vida, pues no lo recogen Huerta Calvo, Peral Vega y Urzáiz Tortajada ni

\footnotetext{
4 Dicha tesis se publicó posteriormente dentro del volumen colectivo coordinado por Ignacio Arellano Ayuso (2007).
} 
tampoco figura en la definición que aporta el DICAT.

El siguiente dato sobre su identidad se remonta al año 1657, momento en el que Rojo formaba parte de la compañía de Juan Pérez de Tapia. Esta información se ha recuperado a partir de un testimonio indirecto, el contrato firmado por el autor de comedias por el que aceptaba llevar a cabo cien representaciones en Granada entre el 27 de mayo de 1657 y el día del Corpus del año siguiente (Llorden, 1975: 195-196). Allí aparece relatada la nómina de representantes que se encargarían de tal labor, entre los que se encontraba José Rojo. Asimismo, el 21 de octubre de 1657, Pérez de Tapia aceptó otro contrato que lo obligaba a representar también en otras ciudades andaluzas, como Carmona, Écija, Málaga o Sevilla. En este nuevo documento también aparece el listado de actrices y actores. Dice:

Biçente de Olmedo, por mí y en nombre de Françisca Besona, mi legítima muger, Alonso de Olmedo $=$ Joseph Rojo $=$ Juan Correa $=$ Joseph Carrillo $=$ Jeronimo de Auila, Melchor Cassas, todos compañeros y representantes en la çiudad de Cádiz, [...]. Firmas: Alonso de Olmedo, Vicente de olmedo, Joseph Rojo, Juo Correa, Jerónimo de abila, Jusepe Carrillo. Cádiz, 21-X-1657 (Agulló y Cobo, 1996: 43).

Otro dato permite ubicar a Rojo en Madrid nuevamente en 1658, si bien es cierto que ofrece una problemática mayor que en los casos anteriores. Se trata de la relación de un gran banquete que se organizó el 20 de febrero en el Retiro de Madrid y al que asistió un gran número de personas vinculadas al mundo dramático. En la lista de asistentes que se refleja al final aparece nada más que el nombre de "Jusepe". La ausencia de apellidos, sobrenombres o cualquier otro tipo de dato que permita precisar la identidad de este sujeto impide afirmar con suficiente seguridad que se trate de José Rojo. Con todo, ya se ha comprobado como la forma "Jusepe" era una de las más populares con las que se conocía al actor en la época, por lo que la hipótesis resulta más que verosímil. Además, es posible redondearla si se atiende al resto de personas que estuvieron presentes durante la copiosa comida. Junto al nombre de Jusepe figuran los de varios actores y actrices que coincidieron con Rojo, por ejemplo, en la misma compañía. Es el caso del propio director, Simón Aguado, que ya se ha mencionado arriba: 
Sin fecha. Archivadas con estos documentos sobre cera hay las cuentas de una "comida que se da en 20 de febrero 1658 en el Retiro", con una lista de platos y 42 personas. Los nombres son como sigue: Vrsola la Roma; Jusepa Lopez; Manuela Escamilla; la Veçona; Luisa Romero; Luciana Leal; Luziana Mejia; Antonia de Santiago; Maria de la O; la Borja; Micaela; Anita; Jusepe; Simon Aguado; Ambrosio Nabarro; Gaspar; seis mujeres del lugar; Pabia; Galindo; Julian; Alonso; el Capuchino; Roquillo [o "Roquielo"']; Santiago; Pedro Fernandez; Auloso [sic] el Tuerto; Juan Ydalgo; don Francisco Clabijo; don Thomas; Baraona; y Trigoso; Pedro de la Rosa; Antonia de la Rosa; Esteban de Llanos; Palomo; Juan Francisco (Shergold y Varey, 1982: 60).

También está documentado que, en 1660, Rojo se encontraba en Sevilla prestando sus servicios como histrión a la compañía de Juana de Cisneros (DICAT, s.v. José Rojo § 1660). El DICAT toma su referencia de Rennert, quien, además de la relación del actor con Juana de Cisneros, menciona a otros dos directores de compañía que supervisaron la labor actoral de Rojo: "actor in the company of Juana de Cisneros in Seville in 1660. He was second barba with Simon Aguado and Juan de la Calle in 1662" (1909: 580). Igualmente valiosa resulta la aportación de Sánchez Arjona, que añade a su estudio el listado completo de representantes que trabajan en la compañía de Juana de Cisneros en 1660 durante las representaciones que se llevaron a cabo en Sevilla en aquel periodo:

La compañía de Juana de Cisneros, que venía trabajando en La Montería antes de la fiesta, constaba, además de la autora, de: Manuel Francisco, Francisco García, Manuel Vallejo, Antonio de Ordaz, Pedro Juan, José Rojo, Cristóbal de Torres, José Carrillo, Juan Antonio de Ayala, Josefa Pavía, María de Zavala, Antonia María, Manuela Maㅡ de Espinosa (1898: 426).

La pista de Rojo se recupera de nuevo en los primeros días del año 1662 gracias a otro contrato. Este garantizaba el trabajo de José Carrillo y su compañía en Segovia desde enero de ese año hasta el Carnaval, y en dicho contrato, como ocurría antes, se relata el total de representantes, donde se incluye a Rojo (Agulló y Cobo, 1983: 112).

Tras los carnavales, el actor y dramaturgo abandonó la compañía de Carrillo. Así lo defiende Rennert sirviéndose de un nuevo acuerdo, firmado el 24 de marzo del mismo año (1909: 580). Allí se establece que Juan de la Calle y Simón Aguado serán los encargados de dirigir la representación del auto sacramental para el día del Corpus en Madrid. Entre la nómina de actores aparece Rojo y se indica que desempeña el papel de barba (Pérez Pastor, 1905: 293). 
Por otro lado, el 25 de junio de ese mismo año la compañía de Aguado debía de haber representado en el madrileño corral del Príncipe el mismo auto que prepararon para el día del Corpus; sin embargo, el corral estaba inhabilitado debido a una serie de obras que fueron necesarias para desmontar la escenografía de otro auto que había quedado censurado por la Inquisición, por lo que hubo que sustituirlo por el de Aguado. José Rojo fue el encargado, en representación de toda la compañía y de su autor, de alegar las causas por las que no pudo llevarse a cabo la representación (Varey y Davis, 1973: 239-240). De mayor importancia resulta para este episodio la labor de Cotarelo y Mori, que logró recuperar el escrito de Rojo:

\begin{abstract}
En Madrid, a 25 de junio, domingo, a las doce, fui al corral de Príncipe y vi estar acabando de poner el teatro donde ha de representar su auto la compañía de Simón Aguado, por haber quitado de dicho corral las apariencias que estaban puestas por el auto de Escamilla, por no haberle podido representar por mandado del tribunal de la Inquisición. Y habiendo visto que la dicha compañía de Simón Aguado no tenía puestos carteles este dicho día, fui al barrio del Mentidero a saber la causa y encontré con Josepe Rojo, representante de dicha compañía, a quien le pregunté la causa de no representar y me dijo que era por ir a hacer a la tarde, a las cuatro, la fiesta que tenían ensayada y estudiada para Aranjuez a sus Majestades en el Retiro; y que mañana lunes por ser día de toros no se representará (1916: 141-142).
\end{abstract}

Aquel verano no fue propicio para Simón Aguado y los representantes con los que trabajaba. Varey y Davis documentan otra incidencia con la representación del auto en el Corral del Príncipe tras el aplazamiento de la primera por cuestiones logísticas. En este caso, el espacio tampoco estaba disponible, debido a que se había cedido en exclusiva para que se ensayase en él otra representación que había de llevarse a escena al día siguiente ante los Reyes. La compañía volvió a requerir la ayuda de Rojo para redactar un documento donde se dejase constancia de la nueva imposibilidad de representar el auto:

28 de junio de 1662. Compañía de Simón Aguado, o por lo menos sus músicos. Música. Retiro. El 27 de junio dijeron al escribano Jusepe Rojo y otros representantes que estaban ensayando "música y tonos para SSMM para mañana noche de san Pedro mientras andan embarcados en el estanque". Al día siguiente los actores dijeron "que SSMM se embarcan al anochecer en el estanque del Retiro y que los tenían músicas alrededor de él y que entre ellas iba la música de la compañía de Simón Aguado con diferentes tonos que para el caso había estudiado (1973: 240).

El último dato recuperado sobre José Rojo procede de 1663. En aquel año, y a pesar de todos los problemas de la temporada previa, la compañía de 
Simón Aguado volvió a encargarse del auto sacramental para festejar el día del Corpus en Madrid. En la lista de actrices y actores que recuperaron Shergold y Varey figura la mención a Rojo como uno de los comediantes que participaron en el mencionado espectáculo, en su caso, como quinto galán:

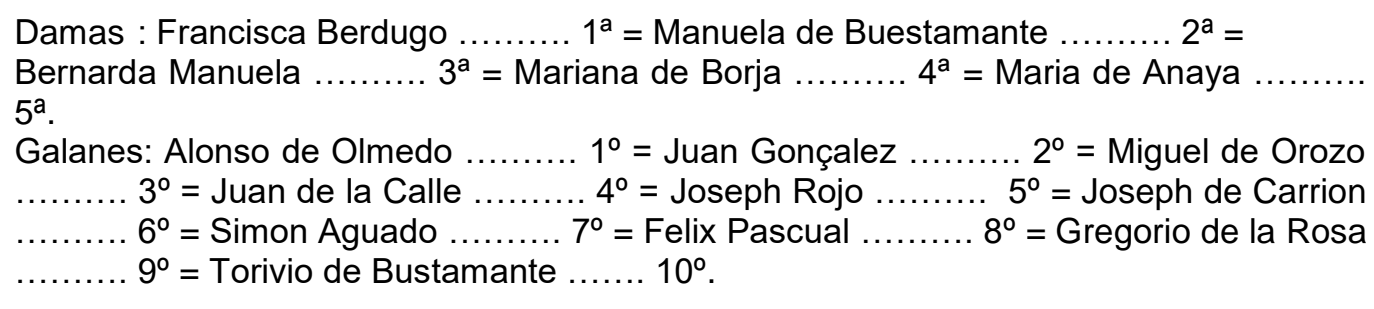

Y el dicho Simon Aguado dijo que se obliga en forma de tener dicha compañía de manifiesto para presentar uno de los autos del Corpus deste presente año (1985: 91).

\section{Conclusiones}

A lo largo de este artículo se ha tratado de dar cuenta de algunas de las dificultades que existen en torno a la biografía de José Rojo. Así, se ha referido, en primer lugar, la problemática con las variantes tanto de su nombre como de su apellido, algunas naturales —Joseph, Jusepe, Josefe; Rojo, Roxo-y otras más complejas -Pedro Royo-.

Con el mismo propósito se han expuesto aquí las confusiones arrastradas por parte de la comunidad investigadora, así como la imposibilidad, ciertamente recurrente, que gran parte de la crítica ha encontrado para aunar en un solo referente las diferentes variantes de la identidad del actor y escritor de Cuenca. Conviene aclarar que la voluntad de ese apartado nunca ha sido señalar los errores de otras investigaciones anteriores de manera que estas pudieran verse desprestigiadas. Todas ellas fueron pioneras en el momento de su redacción y sus conclusiones arrojaron tal cantidad de luz que sin ellas no habría sido posible presentar las que figuran en este trabajo.

El grueso del artículo se ha dedicado a la aportación, justificación, contraste y comprobación de las principales certezas biográficas conservadas sobre Rojo. El resultado más importante ha sido la obtención inequívoca, puesto que procede de un documento firmado por él mismo, de algunos datos fundamentales sobre su vida, como el lugar de nacimiento (Cuenca) o la ciudad donde vivió (Madrid). A estos han de sumarse la localización de su firma, la 
identificación de su producción literaria, que se adhiere a varios géneros, así como otras labores que desempeñó durante su vida, como la de tesorero de la Cofradía de la Novena o la de copista para la compañía de Simón Aguado.

En conclusión, la revisión bibliográfica que se ha realizado en este trabajo $y$, en especial, los resultados arrojados de esta metodología, suponen un nuevo punto de apoyo para proseguir con la tarea de la reconstrucción de las partes más oscuras del teatro áureo; pues, aunque se trata del momento más laureado de la literatura española, ofrece todavía numerosas e interesantes parcelas sobre las que trabajar, bien desde la perspectiva del estudio de las obras, bien desde el estudio directo de quienes las escribieron.

\section{Bibliografía}

(s.a.) (1676): Flor de entremeses, bayles, y loas. Escogidos de los mejores ingenios de España [Texto impreso]. Diego Dormer: Zaragoza.

(s.a. y s.f): "Antíoco y Seleuco", en https://manos.net/manuscripts/bne/16-908antioco-y-seleuco/ [fecha de consulta: 25/07/2021].

(s.a. y s.f.): Llibres de compte $i$ raó de Joan Batiste Luca y Peris, 1650-1651. Llibre d'Albarans [Manuscrito]. Valencia: Archivo General y Fotográfico, V1/vol. 455.

AGULLó Y COBO, Mercedes (1983). "100 documentos sobre el teatro madrileño (1582-1824)". En Andrés Peláez Martín, Fernando Delgado Cebrián y Fernanda Andura Varela (coords.), El teatro en Madrid, 1583-1925. Del corral del Príncipe al teatro de arte. Madrid: Ayuntamiento de Madrid / Delegación de Cultura, pp. 84-135.

AGULLó Y COBO, Mercedes (1996). "Primera entrega documental sobre el teatro en Andalucía". En José Juan Berbel Rodríguez (ed.), En torno al teatro del Siglo de Oro. Actas de las jornadas XII-XIII celebradas en Almería. Almeria: Instituto de Estudios Almerienses / Diputación de Almería, pp. 39-45.

Arellano Ayuso, Ignacio (2007). Comedias burlescas del Siglo de Oro, vol. 6. Madrid / Frankfurt: Iberoamericana / Vervuert.

BarRera y LeIRADO, Cayetano Alberto de la (1860). Catálogo bibliográfico y biográfico del teatro antiguo español, desde sus orígenes hasta mediados del siglo XVIII. Madrid: Imprenta y estereotipia de M. Rivadeneyra.

CAÑAS MURILLO, Jesús (2003). "Teatro y propaganda monárquica en los primeros años de la ilustración: El mejor representante de el catholico coliseo y la exaltación de Fernando VI", Archivum, 52-56, pp. 569-601.

CASAdo Santos, María José (2005). La comedia burlesca en el Siglo de Oro: el rey Perico y la dama tuerta (Diego Velázquez del Puerco), Escanderbey (Felipe López) y Antíoco y Seleúco (de tres ingenios). Estudio, edición y anotación de las tres comedias, tesis doctoral. Navarra: Universidad de Navarra. 
CotARElo y MoRI, Emilio (1916). Actores famosos del siglo XVII: Sebastián de Prado y su mujer Bernarda Ramírez. Madrid: Tipográficas de la Revista de Archivos, Bibliotecas y Museos.

CRESPO MATELLÁN, Salvador (1979). La parodia dramática en la literatura española. Salamanca: Ediciones Universidad de Salamanca.

DOMínGUEZ DE PAZ, Elisa (2014). "La polémica de Zárate/Enríquez Gómez (a propósito de la censura de La conversión de la Magdalena)", Cincinnati Romance Review, 37, pp. 45-66.

Domínguez MAtito, Francisco (2014). “El actor Alonso de Olmedo”, Anuario Calderoniano, 7, pp. 129-147.

EnRíquez GómEZ, Antonio [1647] (2019). Política angélica, Felice Gambin (ed.). Huelva: Servicio de Publicaciones de la Universidad de Huelva.

FERRER VALLS, Teresa (2008). Diccionario biográfico de actores del teatro clásico español (DICAT). Kassel: Reichenberger.

GARCía GonZÁLEZ, Almudena (2012). "El bandolero histórico como personaje de comedia en Lope", Anuario Lope de Vega, 18, pp. 63-79.

Huerta Calvo, Javier, Emilio Peral Vega y Héctor Urzálz Tortajada (2005). Teatro español de la A a la Z. Madrid: Espasa Calpe.

MACKENZIE, Ann L. (1994). Francisco de Rojas Zorrilla y Agustín Moreto: análisis. Liverpool: Liverpool University Press.

GóMEZ, Jesús (1988). El diálogo en el renacimiento español. Madrid: Cátedra.

LLORDEN, Andrés (1975). "Compañías de comedias en Málaga (1572-1800)", Gibralfaro, 27, pp. 169-200.

McGAHA, Michael (1994). "Who was Francisco de Villegas?". En Charles Ganelin y Howard Mancing (eds.), The Golden Age Comedia: Text, Theory and Performance. West Lafayette: Purdue University Press, pp. 165-177.

Montalvo MARECA, Sergio (2019a). "Un diálogo inédito sobre educación femenina: Espejo de ilustres y perfectas señoras". En Ana Abello Verano, Daniele Arciello y Sergio Fernández Martínez (eds.), La lupa y el prisma. Enfoques en torno a la literatura hispánica. León: Universidad de León, Área de Publicaciones, pp. 213-227.

Montalvo MARECA, Sergio (2019b). "Rojo, José. Espejo de ilustres y perfectas señoras", en http://iump.ucm.es/DialogycaBDDH/BDDH328/ [Fecha de consulta: $2 / 11 / 2021]$.

PAZ y MELIA, Antonio (1934). Catálogo de las piezas de teatro, t. I. Madrid: Blass S.A. Tipográfica.

PÉREZ PASTOR, Cristóbal (1901). Nuevos documentos acerca del histrionismo español en los siglos XVI y XVII. Primera serie. Madrid: Imprenta de la Revista Española.

PÉREZ PASTOR, Cristóbal (1905). Documentos para la biografía de D. Pedro Calderón de la Barca. Madrid: Establecimiento tipográfico de Fortanet.

RenNeRT, Hugo A. (1909). The Spanish Stage in the Time of Lope de Vega. New York: The Hispanic Society of America.

Rojo, José (s. XVII). Antíoco y Seleuco: comedia burlesca en tres jornadas [Manuscrito]. Madrid, Biblioteca Nacional de España, mss. 16908.

Rojo, José (ca. 1670). Espejo de ilustres y perfectas señoras [Manuscrito]. Madrid: Biblioteca Nacional de España, mss. 8802.

SÁNCHEZ ARJONA, José (1898). Noticias referentes a los anales del teatro en 
Sevilla desde Lope de Rueda hasta fines del siglo XVII. Sevilla: Imprenta de E. Rasco.

SÁNCHEZ MARIANA, Manuel (1984). "Un manuscrito calderoniano desconocido (con una digresión sobre los autógrafos de Matos Fragoso", Revista de Literatura, n. 91, pp. 121-130.

SheRGold, Norman D. y John E. VAREY (1982). Representaciones palaciegas: 1603-1699. Estudio y documentos. London: Tamesis Books.

SHERGOLD, Norman D. y John E. VAREY (1985). Genealogía, origen y noticias de los comediantes de España. London: Tamesis Books.

URZÁlz TORTAJADA, Héctor (2002). Catálogo de autores teatrales del siglo XVII, vol. 1. Madrid: Fundación Universitaria Española.

URZÁlz TORTAJADA, Héctor (2006). "Ni castigo ni venganza: la figura del rey en Antíoco y Seleúco, de Moreto". En Luciano García Lorenzo (ed.), El teatro clásico español a través de sus monarcas. Madrid: Fundamentos, pp. 237268.

VAREY, John E. y Charles DAVIS (1973). Teatros y comedias en Madrid: 16511665. Estudio y documentos. London: Tamesis Books.

VAREY, John E. y Charles DAVIS (1992). Los libros de cuentas de los corrales de comedias de Madrid: 1706-1719. Estudio y documentos. London: Tamesis Books.

VILLEGAS, Francisco de y José Rojo (s. XVII). Las niñezes de Roldán [Manuscrito]. Madrid: Biblioteca Nacional de España, mss. 18348.

VILlegas, Francisco de y José Rojo [s. XVII] (1758). Comedia famosa. La esclavitud más dichosa y Virgen de los Remedios [Texto impreso]. Barcelona: Pedro Escuder. 